may leave science if they perceive it to reward something other than good research". He feels that the data point towards a thin ice shell but that political powers have marginalized this interpretation and those scientists who advocate it. When discussing his own work, Greenberg generously bestows much credit on his former students, postdocs and colleagues.

In Unmasking Europa, Greenberg succeeds in conveying a story, not of heroes and villains, but about the rise and fall of ideas and how some become accepted for reasons that perhaps go beyond empirical support. In Greenberg's earlier work, Europa the Ocean Moon (Springer, 2005), which is of similar scope but targeted to a research audience, the political storyline is not particularly appropriate. In his latest work, he delivers an accessible and well-laid-out popular-science treatment in which the political narrative is more pertinent, although obviously biased towards his own perspective. Greenberg uses humour to balance out the tone, as in his suggestion that the reader should buy a second copy of the
Europa's fractured icy surface could conceal life beneath.

book just to cut out the images and do the geological reconstructions while reading the first copy.

Tides are the recurring theme of Greenberg's treatment - they "connect the orbits of Jupiter's moons to the geology of Europa, creating environments potentially suitable for life". Only one short chapter deals with the possibility of a biosphere; more detail on the known chemistry of Europa would have been welcomed. Nevertheless, his treatment of tidal dynamics is thorough.

Europa has not yet revealed a smoking gun, as have the icy plumes of Enceladus, to indicate that it is geologically active today. This has left the planetary geology community staring at the limited imagery of Europa, wondering what its surface features reveal about the interior.
Centuries ago, geologists I began adopting the uniformitarian mantra of 'the present being the key to the past'. In the ebb and flow $\frac{y}{z}$ of planetary science, with data streams punctuated by missions that are all too rare, we often find ourselves struggling to decipher the geological present, much less the past.

Unmasking Europa provides a comprehensive and engaging account of Europa's past and present, and sets the stage for the many questions that will be answered by future missions as we continue our search for life beyond Earth.

Kevin P. Hand is a scientist at NASA's Jet Propulsion Laboratory, California Institute of Technology, 4800 Oak Grove Drive, Pasadena, California 91109, USA.

e-mail:khand@jpl.nasa.gov

\title{
Scripting scientists' lives
}

\section{Leave a Light On \\ Ensemble Studio Theatre, New York City 22 January 2009. Part of the First Light Festival, which runs until March 2009}

Last year, at a first reading of her play about the life of biologist Robert Trivers, Ann Marie Healy noticed a stranger in the back of the theatre, laughing. Afterwards, the man strode over to the actor who had played the young biologist as a foul-mouthed and promiscuous genius working out the evolutionary logic of human kindness and conflict, and said: "You got it exactly right." That stranger was Trivers.

Healy's play features in New York's First Light Festival, a collaboration between the Ensemble Studio Theatre and the Alfred P. Sloan Foundation that incubates science-based theatre. The festival, which has run annually for more than a decade, includes nine full-length plays this year and continues until the end of March.

In Leave a Light On, Trivers is portrayed as an ambitious, untenured professor who ruffles feathers at Harvard University's department of zoology as he attempts to take a Darwinian approach to human nature. Dissatisfied with an academic culture that is hostile to his ideas, Trivers retreats to Jamaica to study lizards and then moves to teach at the University of California, Santa Cruz, where he meets Huey
Newton, former leader of the Black Panther party. Widely believed to have dropped 'off the grid', Trivers returns to academia more than a decade later to study the adaptive value of self-deception.

Healy weaves in the science with a light touch. In the play, with the help of a female colleague who is also a love interest, Trivers works out his theory of reciprocal altruism using a series of imaginary birds with distinct approaches to selfless behaviour: Suckers, who always groom their peers; Cheaters, who never do; and Grudgers, who only groom tit-for-tat. As in Tom Stoppard's play Arcadia, the script darts between centuries and characters, punctuating Trivers's sobering career with farcical episodes from the courtship of Charles and Emma Darwin that are meant to explain the logic of gene competition.

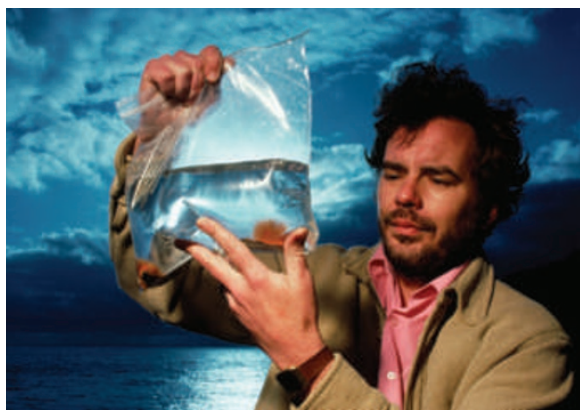

Robert Trivers's ideas on behaviour caused conflict.
The play hardly needs such asides: Trivers's own ideas are enough to drive the plot.

The 2009 First Light Festival began with an uneven selection of one-act plays collectively called $E=m c^{\text {brunch }}$, portraying a chemist discovering her brother's meth lab, an Olympic gymnast trying to prove her rivals are underage, and a mathematician confronting risk in an airport restaurant. The full-length plays take on an equally wide range of topics. Anna Ziegler's Photograph 51 portrays the familiar story of biophysicist Rosalind Franklin, whose X-ray diffraction images led the way to the discovery of DNA structure in 1953. Tommy Smith's Beautiful Night will show Soviet inventor and electronic-music pioneer Léon Theremin falling in love with a black ballerina in New York City in the 1930s - with live accompaniment from the eerie-sounding theremin instrument. And in the improbable monologue Five Easy Steps to Metaphysical Fitness: They Actually Work, comedian Emily Levine will impart wisdom gained by staging a one-woman show about physics while struggling with her pituitary-gland disorder.

"The goal is not just to demystify science but to show its intrinsic appeal, both emotional and intellectual," says Darcy Kelley, a neurobiologist at Columbia University and an adviser to the theatre. "Then science itself becomes a character, not just window dressing."

Jascha Hoffman is a writer based in New York. e-mail: jascha@jaschahoffman.com

See http://tinyurl.com/7otvba for more details on the First Light Festival. 